\title{
Chemical venous thromboembolism prophylaxis in neurosurgical patients: an updated systematic review and meta-analysis
}

\author{
Nickalus R. Khan, MD, ${ }^{1}$ Prayash G. Patel, MD, ${ }^{1}$ John P. Sharpe, MD, ${ }^{2}$ Siang Liao Lee, MD, ${ }^{3}$ and \\ Jeffrey Sorenson, MD ${ }^{1,4}$

\begin{abstract}
Departments of ${ }^{1}$ Neurosurgery and ${ }^{2}$ Surgery-Critical Care, University of Tennessee Health Science Center, Memphis; ${ }^{4}$ Semmes Murphey Neurologic \& Spine Institute, Memphis, Tennessee; and ${ }^{3}$ Department of Neurosurgery, Louisiana State University Health Sciences Center-Shreveport, Louisiana
\end{abstract}

\begin{abstract}
OBJECTIVE Venous thromboembolism (VTE) is a common and potentially life-threatening complication. The risk of serious hemorrhagic complications when starting chemical prophylaxis for VTE prevention is a substantial concern for neurosurgeons. The objective of this study was to perform an updated systematic review and meta-analysis to determine if the rates of VTE and bleeding complications are different in patients undergoing chemoprophylaxis compared with placebo or mechanical prophylaxis alone following cranial or spinal procedures.
\end{abstract}

METHODS In February 2016 a systematic literature review was performed identifying 3944 articles from 4 different databases. A random-effects meta-analysis was performed after identifying the articles that met inclusion criteria.

RESULTS Nine articles that met the inclusion criteria were included. The quality of the studies was good, with all of them being classified as Level 2 evidence, with moderate Jadad scores. A meta-analysis comparing chemoprophylaxis with placebo in the prevention of deep venous thrombosis showed a significant benefit to chemical prophylaxis (OR 0.51 , $95 \% \mathrm{Cl} 0.37-0.71 ; p<0.0001)$. No significant increase in major intracranial hemorrhage $(p=0.60)$, major extracranial hemorrhage $(p=0.98)$, or minor bleeding complications $(p=0.60)$ was found.

CONCLUSIONS Based on moderate-to-good quality of evidence, chemoprophylaxis is beneficial in preventing VTE, with no significant increase in either major or minor bleeding complications in patients undergoing cranial and spinal procedures. Further research is needed to determine whether this conclusion holds true for more specific subpopulations. https://thejns.org/doi/abs/10.3171/2017.2.JNS162040

KEY WORDS deep venous thrombosis; enoxaparin; neurosurgery; heparin; intracranial hemorrhage; pulmonary embolism; review; vascular disorders

$\mathrm{V}$ ENOuS thromboembolism (VTE) is a common lifethreatening complication in patients undergoing neurosurgical procedures. The incidence of deep venous thrombosis (DVT) in this patient population without prophylaxis has been reported to be as high as $34 \%^{3}$ in some studies, with a mean of $16 \%$ across several historical articles. ${ }^{4}$ The length of neurosurgical procedures, delayed ambulation, lengthy hospital stays, and comorbid conditions place this subset of patients at higher risk for VTE. ${ }^{3,18,19,28,29}$ An epidemiological report from 1994 estimated the rate of pulmonary embolism (PE) in neurosurgically treated patients at $0 \%-5 \%$, with a mortality rate rang- ing from $9 \%$ to $50 \% .^{14}$ Additionally, some reports from the mid-1980s have shown the rate of PE to be as high as $25 \%$ in autopsied patients with neurological disorders, and PE was the cause of death in more than half of these. ${ }^{14}$

Despite a multitude of studies evaluating this topic, there is significant debate regarding the best approach for VTE prophylaxis in neurosurgically treated patients. Mechanical prophylaxis has the benefit of being simple without risking significant bleeding complications. However, the rates of VTE with mechanical prophylaxis alone have been shown to be only moderately reduced when compared with placebo groups..$^{25}$ The fear of intracranial and

ABBREVIATIONS DVT = deep venous thrombosis; ECH = extracranial hemorrhage; ICH = intracranial hemorrhage; LMWH = low-molecular-weight heparin; OCEBM = Oxford Centre for Evidence-Based Medicine; PE = pulmonary embolism; RCT = randomized controlled trial; VTE = venous thromboembolism.

SUBMITTED August 4, 2016. ACCEPTED February 9, 2017.

INCLUDE WHEN CITING Published online December 1, 2017; DOI: 10.3171/2017.2.JNS162040. 
intraspinal hemorrhage in the postoperative period persists, limiting the effective use of VTE chemoprophylaxis despite a large body of growing evidence supporting its efficacy. The literature has mixed information with differing levels of evidence on this topic (Table 1). Iorio and Agnelli performed a systematic review 16 years ago that included 4 randomized controlled trials (RCTs) showing a protective benefit from chemical VTE prophylaxis (OR $0.48, \mathrm{p}<0.001)$ and no significant bleeding complications (OR 1.72, p = 0.24). Eight years later, Collen et al. performed a systematic review that included studies without control groups and retrospective studies, with similar results. Glotzbecker et al. and Schuster et al. performed systematic reviews, which were severely limited because they made no formal comparisons (Glotzbecker), used only retrospective studies (Glotzbecker), or had only 2 articles included in the final analysis (Schuster). The latest systematic review was performed 5 years ago by Hamilton et al., and it found a protective benefit (OR 0.58, p < 0.001) from a total of 6 RCTs without bleeding complications ( $p$ $=0.45$ ).

Although each of these systematic reviews performed over the past 16 years provided valuable information, each study has notable limitations, as summarized in Table 1. Thus, the uncertainty of VTE chemoprophylaxis in neurosurgically treated patients persists. Therefore, the purpose of this study was to review and analyze the most powerful and current information evaluating this topic.

The purpose of this study was to provide an updated systematic review and meta-analysis of neurosurgically treated patients receiving chemical prophylaxis to provide the neurosurgeon with concise, up-to-date information on the risks and benefits of chemical VTE prophylaxis.

\section{Methods}

This study was conducted using the Assessment of the Methodological Quality of Systematic Reviews (AMSTAR) measurement tool ${ }^{31}$ and Preferred Reporting Items for Systematic Reviews and Meta-Analyses (PRISMA). ${ }^{24}$

\section{Research Question}

The research question for this study was the following: are the rates of VTE and bleeding complications different in patients undergoing cranial and spinal surgery when using pharmacological prophylaxis compared with placebo or mechanical prophylaxis alone?

\section{Search Strategy}

The systematic search strategy involved a search of multiple electronic databases, bibliographies of relevant articles, and consultation with the senior author. In February of 2016, we electronically searched PubMed/MEDLINE, Clinicaltrials.gov, EMBASE, Google Scholar, The Cochrane Library, and Scopus to find English-language articles (excluding gray literature) with no time-frame restrictions.

The following terms in various combinations were used: "Enoxaparin"; "Heparin"; "Neurosurgery"; "Thromboembolism"; and "Thromboprophylaxis." Two independent researchers (i.e., coauthors on this study), along with librarians at our academic institution, conducted independent literature searches. If there was any question as to the eligibility of an article, consensus was reached through discussion with the senior author. When necessary, additional contact was made with the authors of the included articles to confirm data.

TABLE 1. Prior systematic reviews evaluating neurosurgical VTE prophylaxis

\begin{tabular}{|c|c|c|c|}
\hline $\begin{array}{l}\text { Authors } \\
\text { \& Year }\end{array}$ & Articles Included & VTE & Bleeding Complications \\
\hline $\begin{array}{l}\text { Iorio \& } \\
\quad \text { Agnelli, } \\
2000\end{array}$ & $\begin{array}{l}\text { Included } 4 \text { RCTs (all of } \\
\text { which are included in the } \\
\text { current study) }\end{array}$ & $\begin{array}{l}\text { OR } 0.48, p<0.001 ; 4 \text { studies (in- } \\
\text { cluded in current study) }\end{array}$ & OR $1.72, p=0.24 ; 4$ studies (included in current study) \\
\hline $\begin{array}{l}\text { Collen et } \\
\quad \text { al., } 2008\end{array}$ & $\begin{array}{l}\text { Articles w/o control groups } \\
\quad \& \text { retrospective series }\end{array}$ & $\begin{array}{l}\text { UFH: RR } 0.50 \text { ( } 0.11-2.38) ; 2 \text { studies } \\
\quad \text { (included in current study) } \\
\text { LMWH: RR } 0.60 \text { ( } 0.44-0.81) ; 3 \text { stud- } \\
\quad \text { ies (included in current study) }\end{array}$ & $\begin{array}{l}\text { UFH: RR } 2.11 \text { (0.39-11.31); } 4 \text { studies (included in current study) } \\
\text { LMWH: RR } 1.97 \text { (0.64-6.09); } 4 \text { studies (included in current study) }\end{array}$ \\
\hline $\begin{array}{l}\text { Glotzbecker } \\
\text { et al., } \\
2009\end{array}$ & $\begin{array}{l}25 \text { spinal surgery articles } \\
\text { (included both retrospec- } \\
\text { tive \& prospective trials) }\end{array}$ & $\begin{array}{l}\text { Did not compare chemoprophylaxis } \\
\text { to placebo (no OR or RR avail- } \\
\text { able) }\end{array}$ & $\begin{array}{l}\text { Did not compare chemoprophylaxis to placebo (no OR or RR } \\
\text { available) }\end{array}$ \\
\hline $\begin{array}{l}\text { Schuster et } \\
\text { al., } 2010\end{array}$ & $\begin{array}{l}2 \text { elective thoracolumbar } \\
\text { surgical studies }\end{array}$ & No difference in VTE & $\begin{array}{l}\text { Increased risk of periop bleeding using Coumadin in } 1 \text { of the stud- } \\
\text { ies (this study not included in current analysis) }\end{array}$ \\
\hline $\begin{array}{l}\text { Hamilton et } \\
\text { al., } 2011\end{array}$ & $\begin{array}{l}\text { Elective cranial surgeries (6 } \\
\text { RCTs for main analysis, } \\
2 \text { RCTs compared SQH } \\
\text { to LMWH) }\end{array}$ & $\begin{array}{l}\text { OR } 0.58, p<0.001 \text {; from } 6 \text { pooled } \\
\text { studies (included in current study) }\end{array}$ & $\begin{array}{l}\text { Major ICH: OR 1.48, } p=0.45 ; 6 \text { studies (included in current study) } \\
\text { Major ECH: OR 0.91, } p=0.65 ; 3 \text { studies (included in current study) } \\
\text { Minor ECH: OR 2.28, } p=0.52 ; 2 \text { studies (included in current study) }\end{array}$ \\
\hline $\begin{array}{l}\text { Present } \\
\text { study }\end{array}$ & $\begin{array}{l}9 \text { prospective trials ( } 2 \text { spine, } \\
4 \text { cranial, } 3 \text { cranial \& } \\
\text { spine) }\end{array}$ & $\begin{array}{l}\text { OR } 0.51, p<0.0001 ; 9 \text { studies (Kur- } \\
\text { toglu, Hamidi, Gruber) }\end{array}$ & $\begin{array}{l}\text { Major ICH: OR 1.42, } p=0.42 ; 6 \text { studies (Kurtoglu), did not use } \\
\text { Melon et al. } \\
\text { Major ECH: OR 0.98, } p=0.65 ; 6 \text { studies (Kurtoglu, Hamidi) } \\
\text { Minor ECH: OR 1.28, } p=0.60 ; 4 \text { studies (Kurtoglu) }\end{array}$ \\
\hline
\end{tabular}

$\mathrm{LMWH}=$ low-molecular-weight heparin; $\mathrm{RR}$ = relative risk; $\mathrm{SQH}$ = subcutaneous heparin; UFH = unfractionated heparin. 


\section{Inclusion Criteria, Data Extraction, End Points, Definitions}

The goals of the search were to find articles that met the following inclusion criteria: 1) described a prospective study detailing a group of postoperative, neurosurgically treated, adult patients ( $>18$ years of age) who received chemical VTE prophylaxis; 2) described another group treated with placebo or mechanical prophylaxis; 3) had the use of prophylactic medication as the main treatment difference between the 2 groups; and 4) reported the number of patients and number of events for each group. Thus, noncomparison studies, case reports, and pediatric and retrospective reports were excluded.

Two coauthors of this study (N.R.K. and P.G.P.) screened all potential articles and extracted data independently. The data extracted from each article included the following: 1) dose and type of chemoprophylaxis; 2) total number of participants per group; 3) inclusion and exclusion criteria; 4) rates of VTE in both groups; 4) cointerventions performed along with chemical prophylaxis; 5) the modality used to diagnose VTE; 6) length of follow-up period; and 7) major and minor bleeding complications. Major bleeding was defined as a hemorrhage that changed the morbidity or mortality outcome of the patient or required a return to the operating room. Minor bleeding complications were defined as a drop in hematocrit, microhematuria, or other similar scenarios that did not alter the care of the patient as defined by the respective authors.

The level of evidence for each study was evaluated using the Oxford Centre for Evidence-Based Medicine (OCEBM) guidelines (http://www.cebm.net/ocebmlevels-of-evidence/). Study quality (i.e., assessment of bias within individual studies) was determined using the scale of Jadad et al. ${ }^{17}$ for RCTs. Disagreements among any of the above-mentioned data points were resolved through discussion among the authors.

\section{Meta-Analysis}

For each study, the numbers of VTE events in patients treated with chemical prophylaxis and placebo were identified and an OR was calculated. The overall OR was computed using the method of DerSimonian and Laird. ${ }^{6}$

A random-effects meta-analysis was performed on the selected studies. A random-effects model, in contrast to a fixed-effects model, does not assume that the relative risk is the same across studies and yields a more conservative estimate of effect. Heterogeneity between studies was assessed by the Cochran Q and $\mathrm{I}^{2}$ statistic. Heterogeneity was considered statistically significant when the $\mathrm{p}$ value derived from Cochran $\mathrm{Q}$ was $<0.1$. For the qualitative interpretation of heterogeneity, $\mathrm{I}^{2}$ values of at least $50 \%$ are usually considered to represent substantial heterogeneity, whereas values of at least $75 \%$ indicate considerable heterogeneity, according to the Cochrane Handbook..$^{19}$ Publication bias (i.e., assessment of bias across studies) was graphically evaluated using a funnel plot. . $^{8,32,33}$

\section{Results}

Our search strategy initially identified 3944 articles (Fig. 1). After excluding duplicate studies and articles not directly related to our hypothesis, a total of 32 articles re-

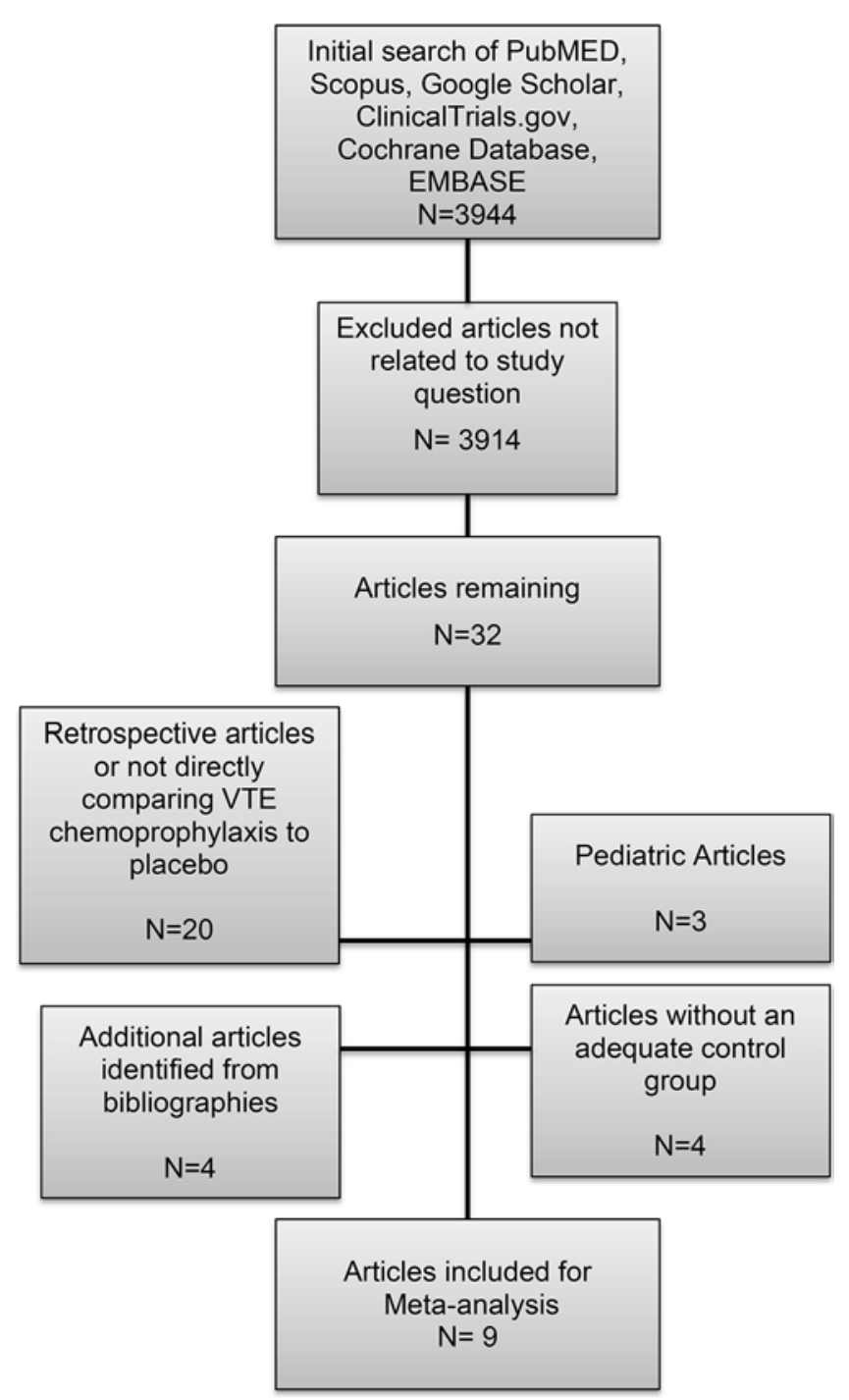

FIG. 1. Flow diagram of search strategy.

mained. Of these, 20 were excluded for being retrospective or not related to the study question, 3 articles ${ }^{11,34}$ were pediatric reports, and 4 articles ${ }^{2,10,21,22}$ did not have a controlled placebo group. This left a total of 5 articles $^{1,5,13,25}$ for inclusion. After searching the bibliographies of all articles, 4 additional papers $3,7,12,20,23$ were identified for inclusion.

\section{Characteristics of Eligible Studies}

The overall quality of included studies was good. All of the included articles except for one ${ }^{7}$ were RCTs. Of these, all but 2 articles ${ }^{3,20}$ were double-blinded. The Jadad score was on average moderate, at $3 \pm 1$ of 5 . Three studies used heparin as the treatment drug and 6 studies used low-molecular-weight heparin (LMWH) (Table 2). Each article was evaluated for quality of evidence using the OCEBM grading system, and all articles were found to be Level 2 of 5. There were 2 articles dedicated only to patients with spine disorders. Three articles included both patients with spine and those with cranial disease; however, only a mi- 


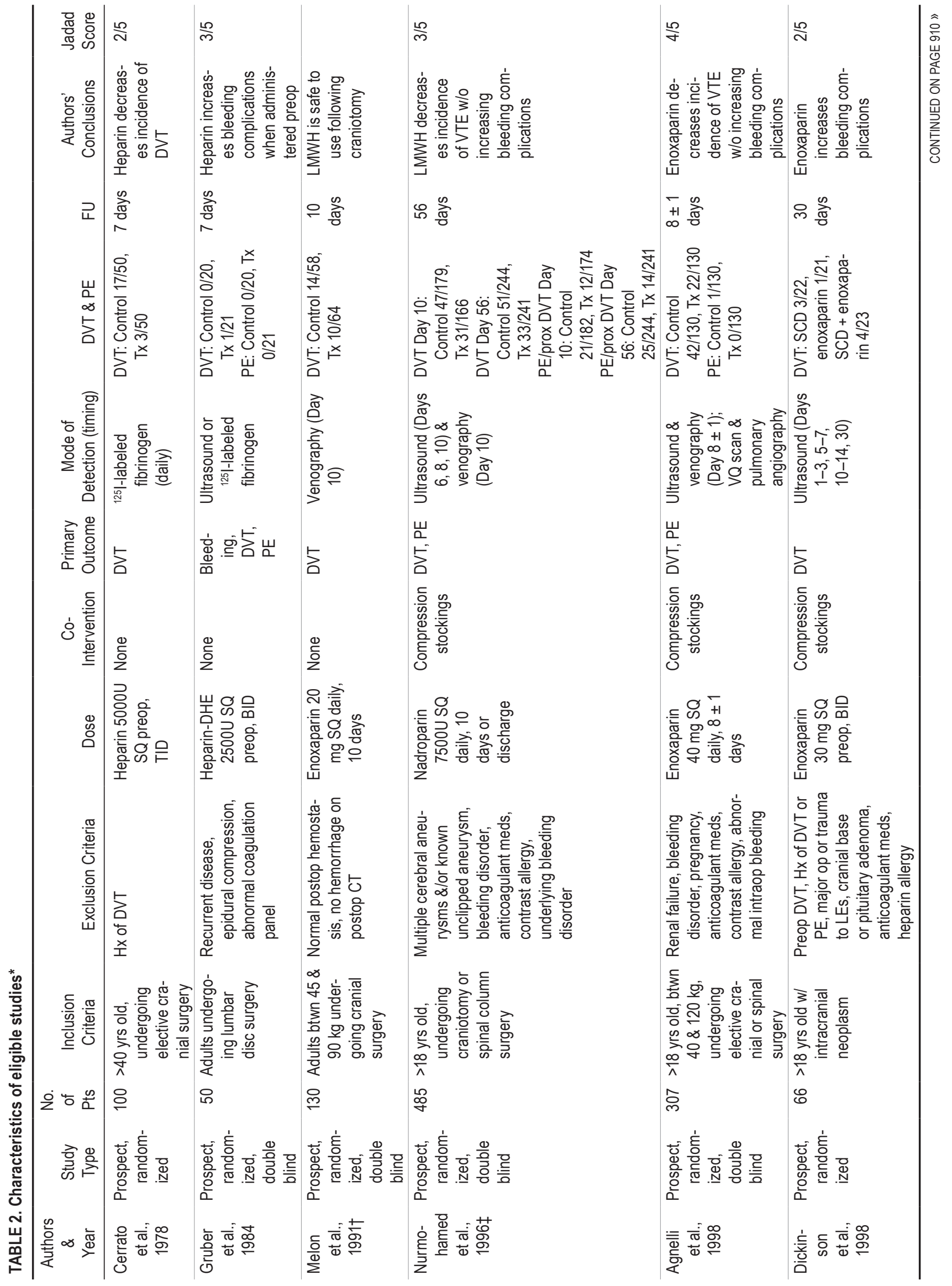




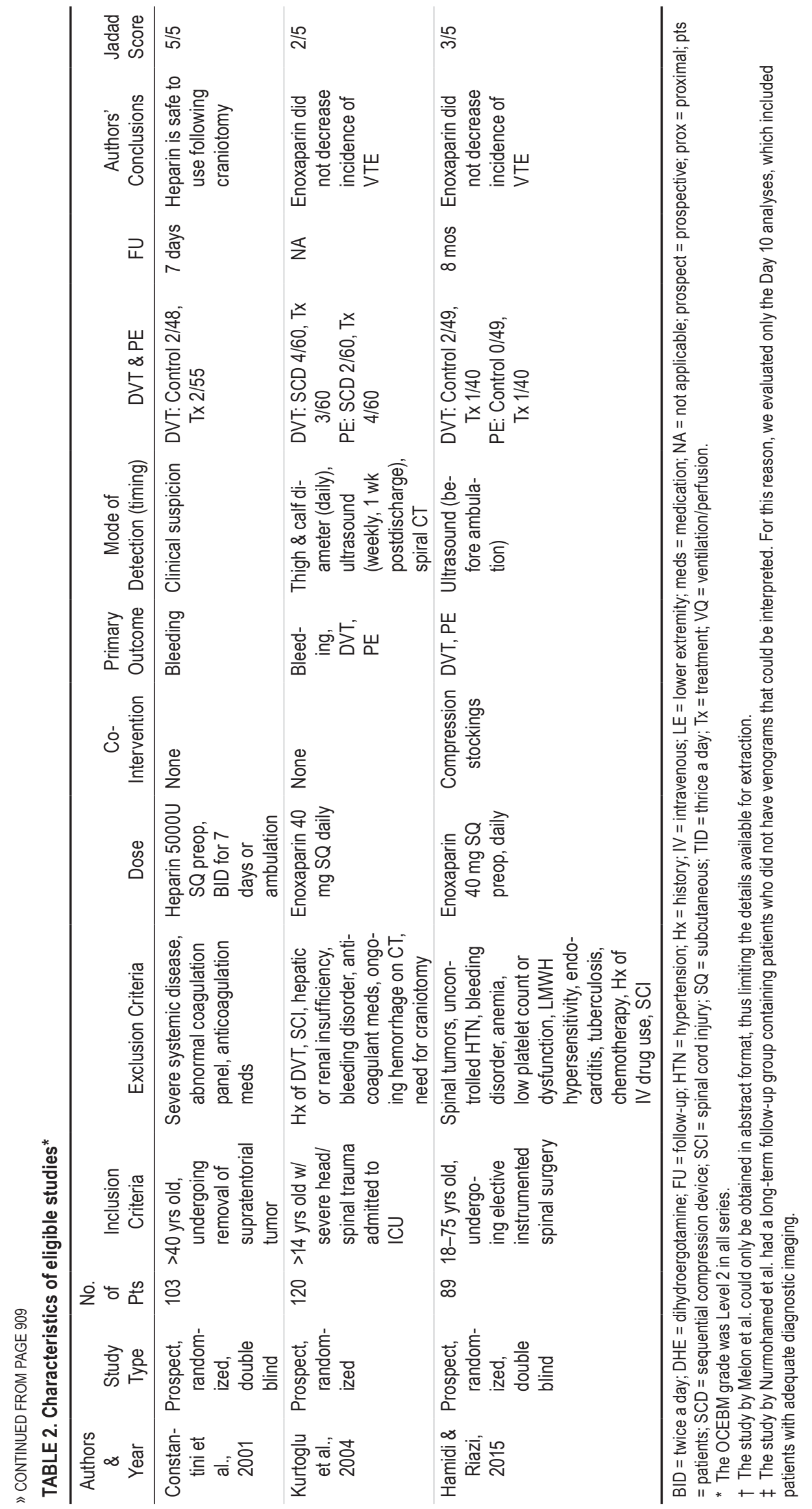




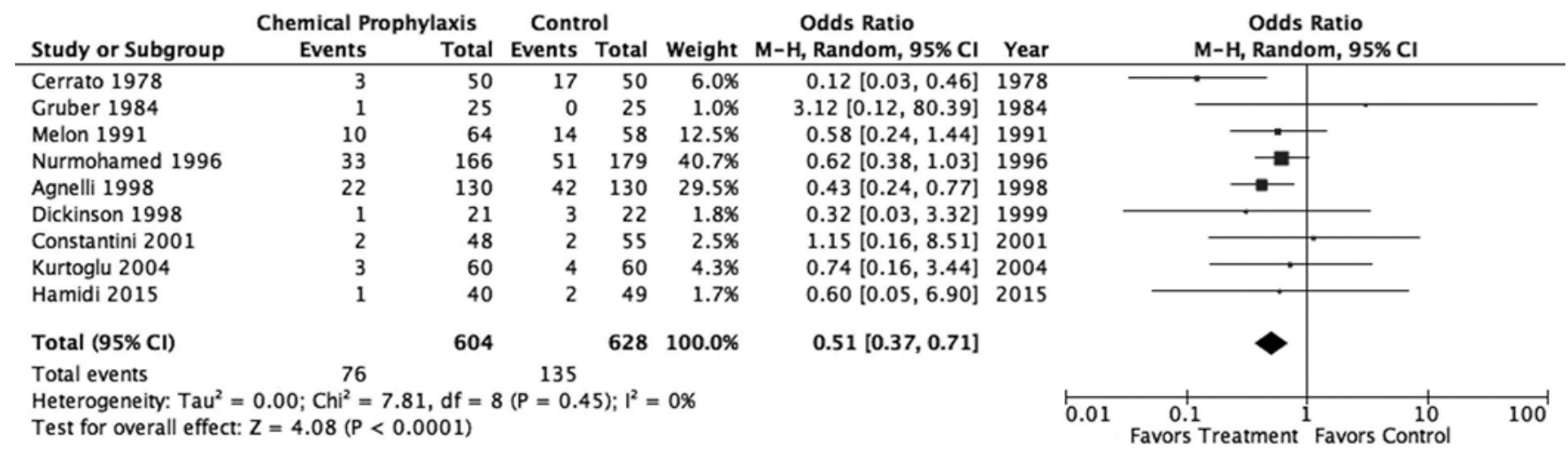

FIG. 2. Forest plot of all studies with their respective OR and $95 \% \mathrm{Cl}$, events (DVT), and overall OR. M-H = Mantel-Haenszel.

nority of them were identified as having spine disorders in each study (Nurmohamed et al., 1.4\%; Agnelli et al., 15\%; Kurtoglu et al., 9.2\%).,20,25

\section{Meta-Analysis}

Deep Venous Thrombosis

A total of 1232 patients were included. The rate of DVT in the treatment group was 76/604 (12.6\%), and it was $135 / 628(21.5 \%)$ in the control group. A meta-analysis comparing chemoprophylaxis with placebo in the prevention of DVT showed a significant benefit from chemical prophylaxis (OR 0.51, 95\% CI 0.37-0.71; $\mathrm{p}<0.0001$ ) (Fig. 2). The absolute risk reduction was $9 \%$ and the relative risk reduction was $42 \%$. The number needed to treat to prevent 1 episode of DVT by using chemoprophylaxis compared with placebo was 11 . The $\mathrm{I}^{2}$ statistic of $0 \%$ indicates no significant heterogeneity in these results. This finding continues to hold true in a subset analysis that included only patients with cranial disorders (OR 0.38, $\mathrm{p}=0.05$ ).

\section{Major Intracranial Hemorrhage}

A total of 1305 patients were included. The rate of major intracranial hemorrhage (ICH) in the treatment group was $18 / 669(2.7 \%)$, and it was $10 / 636(1.6 \%)$ in the control group. A meta-analysis comparing chemoprophylaxis with placebo showed no significant increase in the rate of major ICH (OR 1.42, 95\% CI 0.61-3.30; $p=0.60$ ) (Fig. 3). The $\mathrm{I}^{2}$ statistic of $0 \%$ indicates no significant heterogeneity in these results.

\section{Major Extracranial Hemorrhage}

A total of 1276 patients were included. The rate of major extracranial hemorrhage $(\mathrm{ECH})$ in the treatment group was $4 / 631(0.6 \%)$, and it was $5 / 645(0.8 \%)$ in the control group. A meta-analysis comparing chemoprophylaxis with placebo showed no significant increase in the rate of major ICH (OR 0.98, 95\% CI 0.29-3.36; p = 0.98) (Fig. 4). The $\mathrm{I}^{2}$ statistic of $0 \%$ indicates no significant heterogeneity in these results.

\section{Minor Bleeding Complications}

A total of 1273 patients were included. The rate of minor $\mathrm{ECH}$ in the treatment group was 23/633 (3.6\%), and it was $17 / 640(2.6 \%)$ in the control group. A meta-analysis comparing chemoprophylaxis with placebo showed no significant increase in the rate of minor ECH (OR 1.28, 95\% CI 0.50-3.24; $\mathrm{p}=0.60$ ) (Fig. 5). The $\mathrm{I}^{2}$ statistic of $33 \%$ suggests minimal heterogeneity in these results.

\section{Spinal Hemorrhagic Complications}

The 2 articles that included only spine patients were analyzed to specifically identify if any major spinal hemorrhagic complications were distinguished in the results. The only major spinal hemorrhagic complication, identified by Hamidi and Riazi, ${ }^{13}$ occurred as a result of a laceration of the jugular vein during drain placement (not related to chemoprophylaxis). The other spinal study, by Gruber et al., reported 2 wound hematomas in the placebo group and 2 in the chemoprophylaxis group, and the only minor bleed-

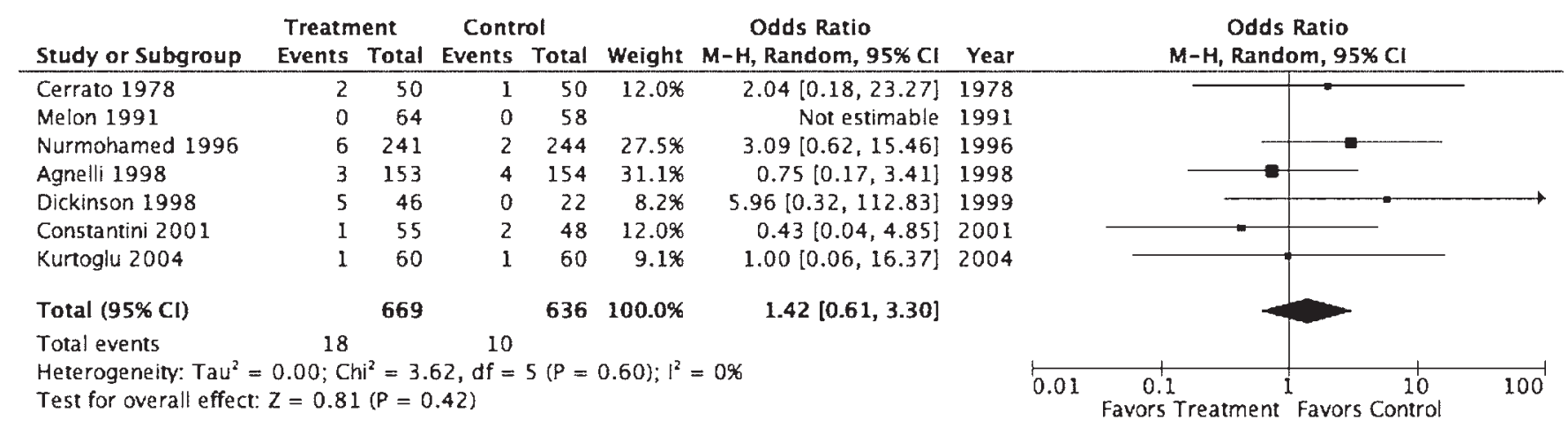

FIG. 3. Forest plot of all studies with their respective OR and $95 \% \mathrm{Cl}$, events (major ICH), and overall OR. 


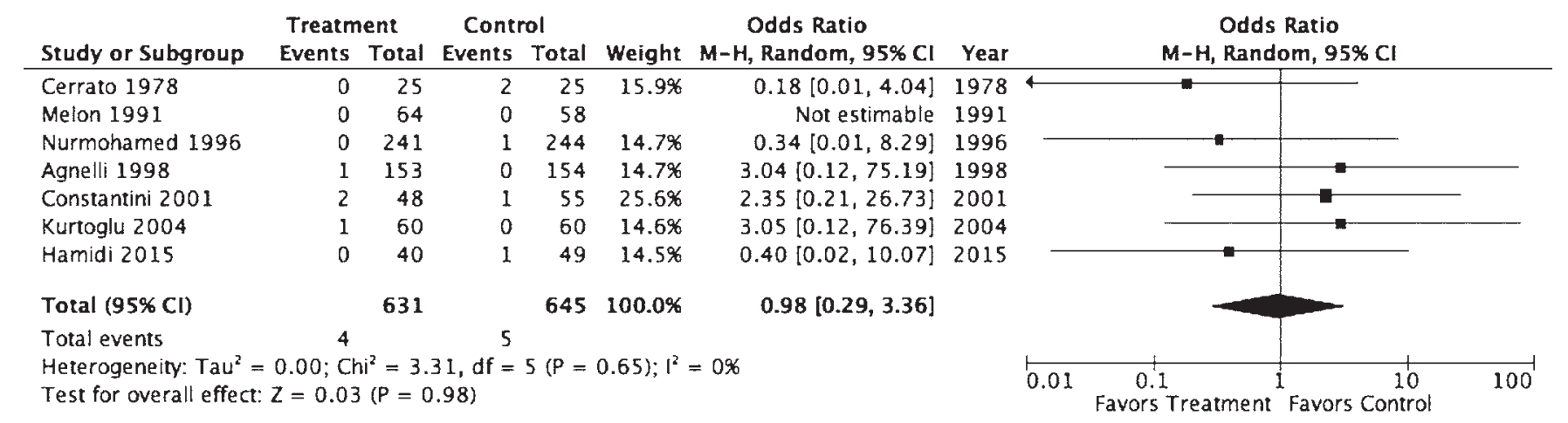

FIG. 4. Forest plot of all studies with their respective OR and $95 \% \mathrm{Cl}$, events (major ECH), and overall OR.

ing complication was increased postoperative drain output in 1 patient. ${ }^{12}$ Additionally, the aforementioned 3 articles, which included a minor proportion of spine patients, did not identify any major spinal hemorrhagic complications in their results.

\section{Publication Bias}

The funnel plot suggests an absence of publication bias, given its overall symmetrical distribution (Fig. 6). The remaining funnel plots for major $\mathrm{ICH}, \mathrm{ECH}$, and minor bleeding complications were all symmetrical.

\section{Sensitivity Analysis}

A sensitivity analysis using the leave-one-out method ${ }^{26}$ was performed by removing each of the first of $\mathrm{K}$ studies and conducting the meta-analysis on the remaining $\mathrm{K}-1$ studies until there were $\mathrm{K}$ distinct meta-analyses. This was performed on each unique outcome to confirm robustness of the analysis. We did not find a significant difference among any of the outcomes evaluated using this method.

\section{Postoperative Subset Analysis}

Only 1 study meeting the criteria included patients who had not undergone surgery. ${ }^{20} \mathrm{~A}$ subset analysis leaving out this study showed no significant change in the results: the OR for VTE was 0.5 (CI 0.35-0.72, $\mathrm{p}=0.0002$ ); for major ICH it was 1.47 (CI $0.61-3.57, p=0.39$ ); for major $\mathrm{ECH}$ it was 0.81 (CI $0.21-3.06, p=0.76)$; and for minor ICH it was 1.97 (CI 0.87-4.45, $\mathrm{p}=0.1$ ).

\section{Discussion}

Patients requiring cranial and spinal surgery present a unique situation of elevated risk for VTE but also high risk for disastrous outcomes should bleeding complications occur in eloquent areas of the brain or spinal cord. Chemical prophylaxis for VTE prevention is an issue neurosurgeons are confronted with on a daily basis. The core of this concern boils down to the following question: does the risk of VTE and its consequences outweigh the risk of potentially catastrophic hemorrhagic complications possible with chemoprophylaxis? The purpose of this study was to critically evaluate the literature and provide an updated systematic review to evaluate both the efficacy of VTE prevention and the risk of bleeding complications when using chemoprophylaxis in patients with neurosurgical diagnoses who are undergoing cranial or spinal surgery.

Five prior systematic reviews concerning this topic exist (Table 1). A meta-analysis of 4 trials $^{1,3,23,25}$ by Iorio and Agnelli in 2000 ${ }^{16}$ found a significant decrease in VTE when using chemoprophylaxis (OR 0.48, p < 0.001). They also found a nonsignificant relative increased risk of major bleeding (OR 1.72, $\mathrm{p}=0.24)$.

Another meta-analysis by Collen et al. from 2008 evaluated both mechanical and chemical prophylaxis. ${ }^{4}$ They included both articles without control groups and retrospective series. They concluded that there was no difference in the rates of ICH and that there was a decrease in DVT when using chemoprophylaxis. A systematic review by Glotzbecker et al. from 2009 looked at 25 spinal sur-

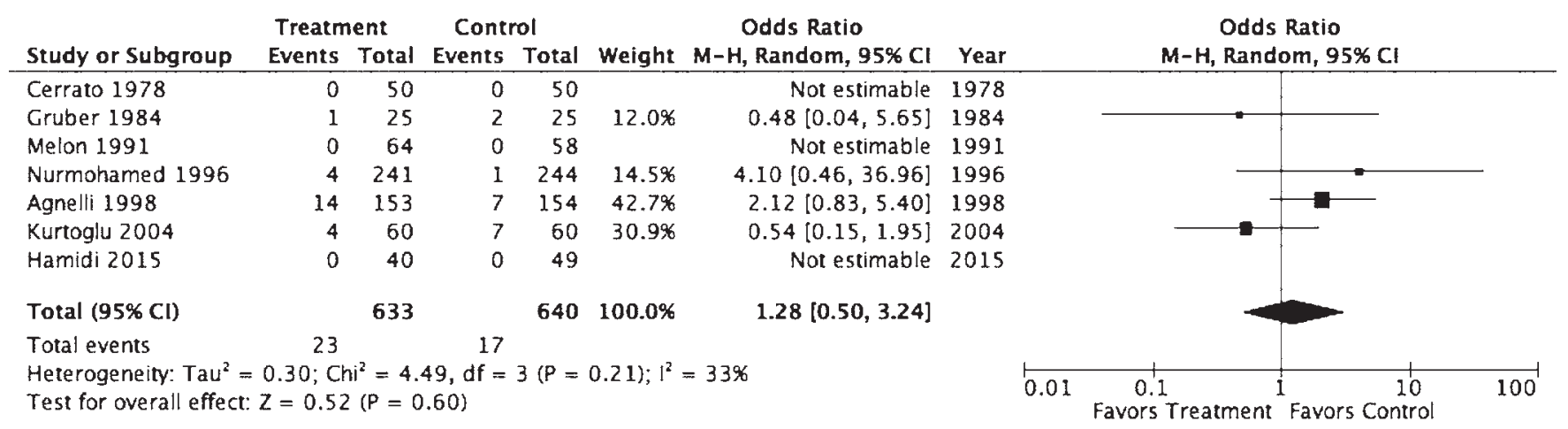

FIG. 5. Forest plot of all studies with their respective OR and $95 \% \mathrm{Cl}$, events (minor ECH), and overall OR. 


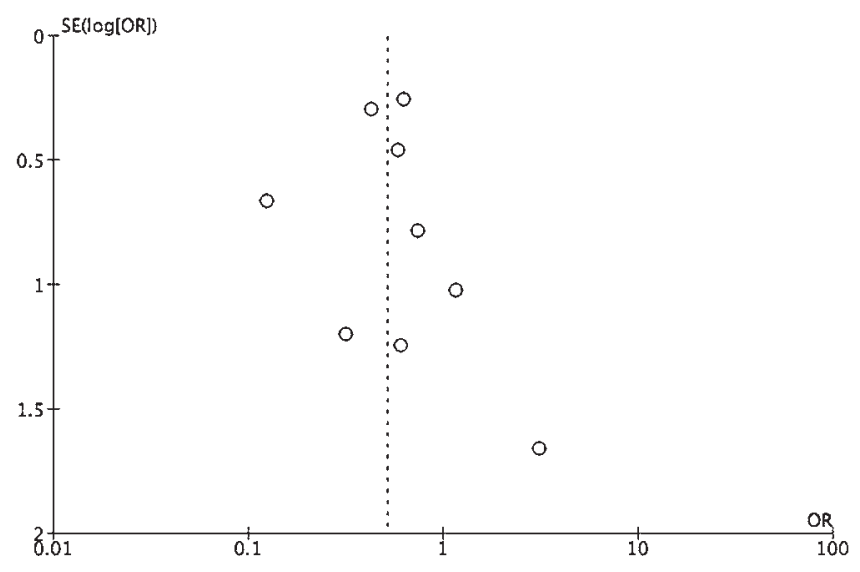

FIG. 6. Funnel plot showing symmetrical distribution of studies, indicating absence of publication bias (DVT).

gery articles and estimated an overall DVT risk of $2.1 \%$. However, this review included both retrospective and prospective articles. It also included different modalities of prophylaxis and did not provide a concrete comparison of the risks and benefits of chemoprophylaxis to discernible control groups. ${ }^{9}$ A review in 2010 by Schuster et al. analyzed only elective thoracolumbar spinal surgeries and included only 2 articles, one of which used Coumadin (warfarin $)^{27}$ as the chemoprophylaxis agent and another ${ }^{12}$ that is included in our current analysis. This review concluded that the incidence of DVT and PE is very low, and did not recommend the use of chemical prophylaxis..$^{30} \mathrm{~A}$ review in 2011 by Hamilton et al. looked specifically at RCTs of elective cranial surgeries, examining chemoprophylaxis versus placebo. They found $6 \mathrm{RCTs}^{1,3,5,7,23,25}$ that showed a significant risk reduction of VTE with use of chemoprophylaxis (OR $0.58, \mathrm{p}<0.001$ ), in conjunction with a nonsignificant increase in the incidence of associated ICH in the treatment groups. ${ }^{15}$

In the current analysis, we provide an updated comparison of chemical versus mechanical prophylaxis or placebo for VTEs for patients undergoing cranial or spinal surgery, and evaluated potential benefits and hemorrhagic compli- cations. In comparison with prior systematic reviews, our study has included 3 studies that were not included in the most recent update in $2011,{ }^{15}$ and 5 more than the original systematic review on this topic. ${ }^{16}$ Additionally, only prospective studies were included in the present study, compared with the systematic reviews performed by Glotzbecker et al. ${ }^{9}$ and Collen et al. ${ }^{4}$ (Table 1 ).

We include both cranial and spinal procedures to estimate the efficacy of VTE prevention (Table 2). Several of these articles included patients with both cranial and spinal disorders, ${ }^{1,20,25}$ whereas others did not. ${ }^{3,5,7,12,13,23} \mathrm{We}$ also include only prospective studies that clearly delineate a comparison of a nonchemical control group or placebo. Our analysis of included studies suggests a significant benefit to using chemical prophylaxis in the prevention of VTE (Fig. 2). The findings in this study are in general agreement with the prior estimates from pooled analysis. ${ }^{1,15} \mathrm{We}$ also found a nonsignificant increase in the rate of major $\mathrm{ICH}$, no difference in major $\mathrm{ECH}$, and a nonsignificant increase in minor bleeding complications (Figs. 3-5). The overall rates of bleeding complications in treatment and placebo arms are listed by study in Table 3 .

\section{Limitations of the Study}

The strengths of the recommendations from a metaanalysis are only as robust as the quality of articles from which they are derived. The majority of articles included in this analysis were blinded RCTs with moderate quality. However, the population of patients, dosage and type of chemoprophylaxis, timing of chemoprophylaxis, and methods of VTE detection were heterogeneous. Although this study provides an estimate of the risks and benefits of using chemoprophylaxis in a general neurosurgical population, these findings cannot be applied to unique groups of patients who may be at a higher risk versus those at a lower risk-for example, a patient with a ruptured aneurysm compared with a patient undergoing an uncomplicated elective lumbar discectomy. More research and RCTs are needed to further define the optimal use of chemoprophylaxis in specific neurosurgical subpopulations.

TABLE 3. Literature review of bleeding complications of chemoprophylaxis compared to placebo

\begin{tabular}{|c|c|c|c|c|c|c|}
\hline \multirow[b]{2}{*}{ Authors \& Year } & \multicolumn{2}{|r|}{ Major ICH } & \multicolumn{2}{|c|}{ Major ECH } & \multicolumn{2}{|c|}{ Minor Bleeding Complications } \\
\hline & Control & $\mathrm{Tx}$ & Control & $\mathrm{Tx}$ & Control & $\mathrm{Tx}$ \\
\hline Cerrato et al., 1978 & $1 / 50$ & $2 / 50$ & NA & NA & $0 / 50$ & $0 / 50$ \\
\hline Gruber et al., 1984 & NA & NA & $2 / 25$ & $0 / 25$ & $2 / 25$ & $1 / 25$ \\
\hline Melon et al., 1991 & $0 / 58$ & $0 / 64$ & $0 / 58$ & $0 / 64$ & $0 / 58$ & $0 / 64$ \\
\hline $\begin{array}{l}\text { Nurmohamed et al., } \\
\quad 1996\end{array}$ & $1 / 244$ & $6 / 241$ & $1 / 244$ & $0 / 241$ & $1 / 244$ & $4 / 241$ \\
\hline Agnelli et al., 1998 & $4 / 154$ & $3 / 153$ & $0 / 154$ & $1 / 153$ & $7 / 154$ & $14 / 153$ \\
\hline Dickinson et al., 1998 & $0 / 22$ & $\begin{array}{c}\text { Enoxaparin 2/21, } \\
\text { enoxaparin + SCD 3/23 }\end{array}$ & NA & NA & SCD: 0/22 & $\begin{array}{c}\text { Enoxaparin 0/21, } \\
\text { enoxaparin + SCD 0/23 }\end{array}$ \\
\hline Constantini et al., 2001 & $2 / 48$ & $1 / 55$ & $1 / 48$ & $2 / 55$ & NA & NA \\
\hline Kurtoglu et al., 2004 & $1 / 60$ & $1 / 60$ & $0 / 60$ & $1 / 60$ & $4 / 60$ & $7 / 60$ \\
\hline Hamidi \& Riazi, 2015 & $0 / 49$ & $0 / 40$ & $1 / 49$ & $0 / 40$ & $0 / 49$ & $0 / 40$ \\
\hline Total & $9 / 685(1.3 \%)$ & $16 / 707(2.3 \%)$ & $5 / 638(0.78 \%)$ & $5 / 638(0.78 \%)$ & $14 / 662(2.1 \%)$ & $26 / 677(3.8 \%)$ \\
\hline
\end{tabular}




\section{Study Implications}

Our study provides an up-to-date evaluation of the literature from across the world of the general estimate of the risks and benefits of using chemoprophylaxis in patients undergoing cranial or spinal procedures. We found, based on moderate-to-good quality of evidence trials, that chemoprophylaxis is beneficial in preventing VTE while resulting in no statistically significant increase in bleeding complications (both minor and major).

\section{Conclusions}

Based on the moderate-to-good quality of evidence, chemoprophylaxis is beneficial in preventing VTEs in patients undergoing management of cranial or spinal pathology, with no significant increase in either major or minor bleeding complications. The adverse impact of VTE in untreated patients appears to outweigh that of hemorrhage in patients receiving chemoprophylaxis. Further research is needed to determine whether this conclusion holds true for more specific subpopulations, and for the optimal timing for initiation of chemoprophylaxis.

\section{Acknowledgments}

We thank Andrew J. Gienapp, BA (Department of Medical Education, Methodist University Hospital, Memphis, TN; and Department of Neurosurgery, University of Tennessee Health Science Center, Memphis, TN) for technical and copy editing, preparation of the manuscript and figures for publishing, and publication assistance with this manuscript.

\section{References}

1. Agnelli G, Piovella F, Buoncristiani P, Severi P, Pini M, D’Angelo A, et al: Enoxaparin plus compression stockings compared with compression stockings alone in the prevention of venous thromboembolism after elective neurosurgery. $\mathbf{N}$ Engl J Med 339:80-85, 1998

2. Boström S, Holmgren E, Jonsson O, Lindberg S, Lindström $\mathrm{B}$, Winsö I, et al: Post-operative thromboembolism in neurosurgery. A study on the prophylactic effect of calf muscle stimulation plus dextran compared to low-dose heparin. Acta Neurochir (Wien) 80:83-89, 1986

3. Cerrato D, Ariano C, Fiacchino F: Deep vein thrombosis and low-dose heparin prophylaxis in neurosurgical patients. J Neurosurg 49:378-381, 1978

4. Collen JF, Jackson JL, Shorr AF, Moores LK: Prevention of venous thromboembolism in neurosurgery: a metaanalysis. Chest 134:237-249, 2008

5. Constantini S, Kanner A, Friedman A, Shoshan Y, Israel Z, Ashkenazi E, et al: Safety of perioperative minidose heparin in patients undergoing brain tumor surgery: a prospective, randomized, double-blind study. J Neurosurg 94:918-921, 2001

6. DerSimonian R, Laird N: Meta-analysis in clinical trials. Control Clin Trials 7:177-188, 1986

7. Dickinson LD, Miller LD, Patel CP, Gupta SK: Enoxaparin increases the incidence of postoperative intracranial hemorrhage when initiated preoperatively for deep venous thrombosis prophylaxis in patients with brain tumors. Neurosurgery 43:1074-1081, 1998

8. Egger M, Davey Smith G, Schneider M, Minder C: Bias in meta-analysis detected by a simple, graphical test. BMJ 315:629-634, 1997

9. Glotzbecker MP, Bono CM, Wood KB, Harris MB: Thromboembolic disease in spinal surgery: a systematic review. Spine (Phila Pa 1976) 34:291-303, 2009
10. Goldhaber SZ, Dunn K, Gerhard-Herman M, Park JK, Black PM: Low rate of venous thromboembolism after craniotomy for brain tumor using multimodality prophylaxis. Chest 122:1933-1937, 2002

11. Gonda DD, Fridley J, Ryan SL, Briceño V, Lam SK, Luerssen TG, et al: The safety and efficacy of use of low-molecularweight heparin in pediatric neurosurgical patients. J Neurosurg Pediatr 16:329-334, 2015

12. Gruber UF, Rem J, Meisner C, Gratzl O: Prevention of thromboembolic complications with miniheparin-dihydroergotamine in patients undergoing lumbar disc operations. Eur Arch Psychiatry Neurol Sci 234:157-161, 1984

13. Hamidi S, Riazi M: Incidence of venous thromboembolic complications in instrumental spinal surgeries with preoperative chemoprophylaxis. J Korean Neurosurg Soc 57:114118,2015

14. Hamilton MG, Hull RD, Pineo GF: Venous thromboembolism in neurosurgery and neurology patients: a review. Neurosurgery 34:280-296, 1994

15. Hamilton MG, Yee WH, Hull RD, Ghali WA: Venous thromboembolism prophylaxis in patients undergoing cranial neurosurgery: a systematic review and meta-analysis. Neurosurgery 68:571-581, 2011

16. Iorio A, Agnelli G: Low-molecular-weight and unfractionated heparin for prevention of venous thromboembolism in neurosurgery: a meta-analysis. Arch Intern Med 160:23272332, 2000

17. Jadad AR, Moore RA, Carroll D, Jenkinson C, Reynolds DJ, Gavaghan DJ, et al: Assessing the quality of reports of randomized clinical trials: is blinding necessary? Control Clin Trials 17:1-12, 1996

18. Joffe SN: Incidence of postoperative deep vein thrombosis in neurosurgical patients. J Neurosurg 42:201-203, 1975

19. Kayser-Gatchalian MC, Kayser K: Thrombosis and intracranial tumors. J Neurol 209:217-224, 1975

20. Kurtoglu M, Yanar H, Bilsel Y, Guloglu R, Kizilirmak S, Buyukkurt D, et al: Venous thromboembolism prophylaxis after head and spinal trauma: intermittent pneumatic compression devices versus low molecular weight heparin. World J Surg 28:807-811, 2004

21. Macdonald RL, Amidei C, Baron J, Weir B, Brown F, Erickson RK, et al: Randomized, pilot study of intermittent pneumatic compression devices plus dalteparin versus intermittent pneumatic compression devices plus heparin for prevention of venous thromboembolism in patients undergoing craniotomy. Surg Neurol 59:363-374, 2003

22. Macdonald RL, Amidei C, Lin G, Munshi I, Baron J, Weir BK, et al: Safety of perioperative subcutaneous heparin for prophylaxis of venous thromboembolism in patients undergoing craniotomy. Neurosurgery 45:245-252, 1999

23. Melon E, Keravel Y, Gaston A, Huet Y, Combes S, et al: Deep venous thrombosis prophylaxis by low molecular weight heparin in neurosurgical patients. Anesthesiology 75:A214, 1991 (Abstract)

24. Moher D, Liberati A, Tetzlaff J, Altman DG: Preferred reporting items for systematic reviews and meta-analyses: the PRISMA statement. PLoS Med 6:e1000097, 2009

25. Nurmohamed MT, van Riel AM, Henkens CM, Koopman MM, Que GT, d'Azemar P, et al: Low molecular weight heparin and compression stockings in the prevention of venous thromboembolism in neurosurgery. Thromb Haemost 75:233-238, 1996

26. Patsopoulos NA, Evangelou E, Ioannidis JP: Sensitivity of between-study heterogeneity in meta-analysis: proposed metrics and empirical evaluation. Int J Epidemiol 37:1148-1157, 2008

27. Rokito SE, Schwartz MC, Neuwirth MG: Deep vein thrombosis after major reconstructive spinal surgery. Spine (Phila Pa 1976) 21:853-859, 1996 
28. Ruff RL, Posner JB: Incidence and treatment of peripheral venous thrombosis in patients with glioma. Ann Neurol 13:334-336, 1983

29. Sawaya R, Zuccarello M, Elkalliny M, Nishiyama H: Postoperative venous thromboembolism and brain tumors: Part I. Clinical profile. J Neurooncol 14:119-125, 1992

30. Schuster JM, Fischer D, Dettori JR: Is chemical antithrombotic prophylaxis effective in elective thoracolumbar spine surgery? Results of a systematic review. Evid Based Spine Care J 1:40-45, 2010

31. Shea BJ, Grimshaw JM, Wells GA, Boers M, Andersson N, Hamel C, et al: Development of AMSTAR: a measurement tool to assess the methodological quality of systematic reviews. BMC Med Res Methodol 7:10, 2007

32. Sterne JA, Egger M: Funnel plots for detecting bias in metaanalysis: guidelines on choice of axis. J Clin Epidemiol 54:1046-1055, 2001

33. Sterne JA, Egger M, Smith GD: Systematic reviews in health care: Investigating and dealing with publication and other biases in meta-analysis. BMJ 323:101-105, 2001

34. Tabori U, Beni-Adani L, Dvir R, Burstein Y, Feldman Z, Pessach I, et al: Risk of venous thromboembolism in pediatric patients with brain tumors. Pediatr Blood Cancer 43:633636,2004

\section{Disclosures}

The authors report no conflict of interest concerning the materials or methods used in this study or the findings specified in this paper.

\section{Author Contributions}

Conception and design: Sorenson, Khan. Acquisition of data: Khan, Patel, Lee. Analysis and interpretation of data: Khan, Patel. Drafting the article: Khan, Patel. Critically revising the article: all authors. Reviewed submitted version of manuscript: Sorenson, Khan, Sharpe, Lee. Approved the final version of the manuscript on behalf of all authors: Sorenson. Statistical analysis: Khan. Study supervision: Sorenson.

\section{Correspondence}

Jeffrey Sorenson, Semmes Murphey Neurologic \& Spine Institute, 6325 Humphreys Blvd., Memphis, TN 38120.email: jsorenson@ semmes-murphey.com. 